\title{
A methodology based on numerical simulation to study river floods.
} Application to lower river Omaña basin

\author{
Raquel Martínez-Cantó ${ }^{a, *}$ and Arturo Hidalgo ${ }^{a, b, * *}$ \\ ${ }^{a}$ Departamento de Ingeniería Gelógica y Minera. E.T.S.I. de Minas y Energía. Universidad \\ Politécnica de Madrid, Madrid, Spain \\ ${ }^{b}$ Center for Computational Simulation. Universidad Politécnica de Madrid, Madrid, Spain \\ *e-mail: raquel.martinez.canto@alumnos.upm.es \\ **e-mail: arturo.hidalgo@upm.es
}

\begin{abstract}
The river floods happening in populated areas are serious natural risks that give rise to human and economic losses. In order to predict the consequences of river floods and to implement preventive and corrective measures, the mathematical modelling and numerical simulation play, nowadays, a very important role. Among the wide variety of software available for the numerical simulation in fluvial dynamics we have used, in this work, the hydrodynamic model IBER, which is free access simulation software for solving 2D shallow water models. In this paper we focus our attention in floods happening in the vicinity of the confluence of two rivers where there are also crops, with economic importance for the inhabitants of the area that may be affected by the inundation. As an example of this type of geographical region we have used data obtained from the region Las Omañas in NW Spain where, although there is the confluence of rivers Luna and Omaña, the confluence region does not belong to the study area, since we pay our attention to the inundations happening in the village Las Omañas, which is due to the action of one of both rivers, namely the river Omaña. Keywords: Open channel flow, Shallow water equations, Fluvial processes modelling, Flood modelling, Finite volume method, Freeware Iber.
\end{abstract}

\section{INTRODUCTION}

River floods are natural risks that produce important human and economic losses. According to the Directive on floods of the European Union 2007/60/CE, a flood is the "occupation by water of terrains that before were free of it" (Official Journal of the European Union, 288, 2007-11-06, 27-34) which is due to river floods, ice melting, ravines due to strong rains, tsunamis, among others [17]. Also some authors [2] propose that climatic change can affect rivers flooding at a global scale. The river floods occur when the flow rate of the 
river overtops its banks which yields the flooding [4]. The analysis of fluvial dynamics, which includes the knowledge of water heights and velocities, is essential to determine the water flow rates which give rise to the appearance of floods, and also to be able to implement corrective and preventive actions [1]. Moreover, the consideration of cartographic techniques and the aid of Geographical Information Systems allow to establish actions to recover the affected terrains [17]. The so called flash flood is caused by a sudden increase of the river stream flow usually produced by heavy rainfall concentrated in a short period of time (see for instance [12], [16]). These types of floods are short-term processes that can last from minutes to hours, and they are typical of small mountainous basins ([3], [18]). In risk assessment of floods, numerical modelling is a fundamental technique to study the dynamics of the river, both during its regular regime and in the case of flooding. Therefore it is very useful to analyse the effect of possible preventive and corrective actions in river floods management.

We are concerned with floods that take place in the surroundings of the confluence of rivers and affect populated areas and crops, which are usually livelihoods of the population in that region. The interest of considering this configuration is that they are present in several geographical regions. We can mention several examples such as the region of Bavaria (Germany), close to the city of Hallertau or the region of Rakovnik, in Czech Republic were there are records of inundations which affected the crops of hop plants. Some other examples of places in which the convergence of rivers has caused severe inundations affecting populated areas and crops are Nauta (Perú), Francisco de Orellana (Ecuador) or Ghirano (Italy). 


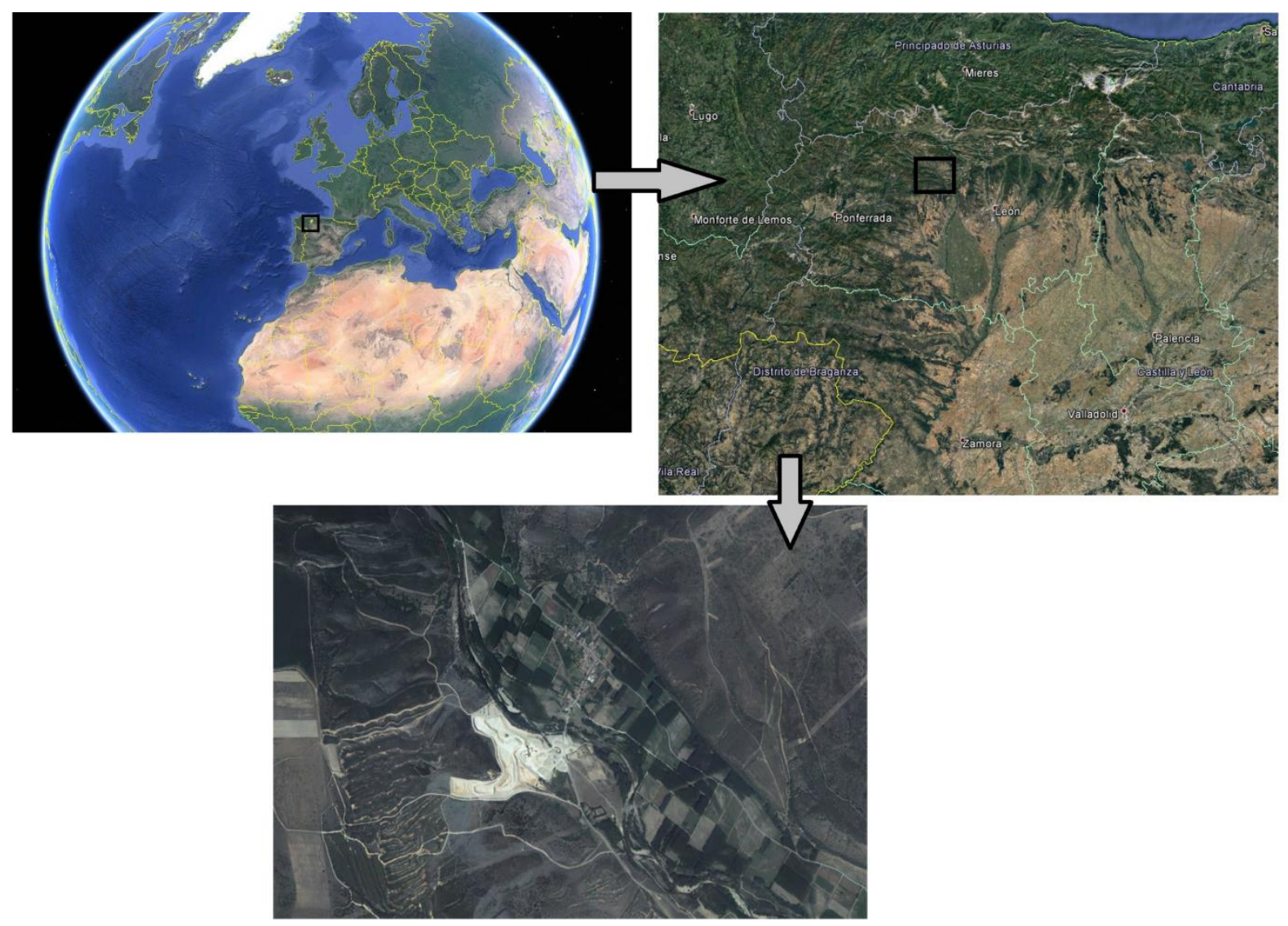

Fig. 1. Geographical situation of the study area.

In this latter case, during the period 2002-2007, a dike was built but it was only a partial solution to the problem. In this work we consider a region with similar characteristics of the aforementioned ones, where rivers Luna and Omaña converge to give rise to river Orbigo, situated in NW Spain. In this region there are crops of hop plants, which represent more than $90 \%$ of the hop production in Spain. The particular application given in this work concerns the inundations happening in the village Las Omañas, which are influenced mainly by the river Omaña, therefore, the study area does not consider the confluence of both rivers but the region affected by the inundations.

The mathematical models commonly used are based on the shallow water equations, which are a set of conservation laws involving water height and momentum (see for instance [5], [8], [13], [14], [15], [19], [20] among meny others). In shallow water models the vertical component of the velocity is assumed negligible compared to the horizontal one, which is realistic in the context of river flows and water flow in channels. There is a vast variety of commercial software that has been developed for simulating river dynamics. In this work we have resorted to use the software IBER, since it is a freeware very useful to deal with $2 \mathrm{D}$ 
water simulation [7], [10], although other numerical codes could have been chosen, perfectly well. Although this software is widely used, to the best of our knowledge it has not been previously applied to the type of regions of interest in this work and, therefore, there are no references in literature on this particular application. Another goal of this work is the introduction of dikes in the simulation with the aim of reducing the effects of the floods in populated zones, which also represents a novel application of this software.

The rest of this paper is organized as follows. In the next section we describe the area of application considered in this work, followed by the materials and methods used. Afterwards some numerical results are shown. Finally conclusions and prospective lines related to this work are given.

\section{Area of application}

As mentioned above we pay our attention to a region called Las Omañas located in NW Spain on the banks of the river Omaña, between the Cantábrica Range and the Órbigo basin. The study area is shown in figure 1 .

Concerning the river Omaña, it runs in direction NW-SE and goes through narrow valleys -in Paleozoic materials. When these rivers reach Las Omañas region, they become rivers of plain and go through marls and clays [17].

On the mountains, the rainfall is above 1000 or $1500 \mathrm{~mm}$, while in plain zones rainfall is moderate (400 or $600 \mathrm{~mm}$ ). This fact has an important effect on the behaviour of the rivers under study and the probability of floods to take place.

The municipality of Las Omañas has suffered flood events linked to the river Omaña that date back to the Early Middle Ages, as attested by documentary records that existed in the late fifteenth century. According to the information registered, these floods cut roads and caused serious damages to buildings. The most recent events that took place in the 1990s and in the early 2000s caused important economic losses and put part of the local population at risk. As a matter of fact, the village of Las Omañas suffers frequent inundations due to overflows of the rivers under study.

\section{MATERIAL AND METHODS}

We are concerned with numerical simulation of river dynamics and the prediction of floods. Therefore a fundamental tool in this analysis is the software to solve the mathematical models. In this case, as mentioned before, we utilize the computational tool IBER [10], [11] which, in order to yield realistic results, requires a wide knowledge of the region under study. We use data given by the Digital Terrain Model (DTM), also values of water flow rates and 
aerial photographs (i.e. orthophoto). This data have been provided by the Instituto Geográfico Nacional of Spain (IGN) and from the Hydrographic Confederation. Once the orthophoto and the DTM have been exported, the next step is the use of the Rectangular Triangular irregular Network (RTIN), to generate the mesh in the geometry, for which a tolerance of $0.2 \mathrm{~m}$ has been chosen. In order to optimize the computation time and the accuracy of the results, it is better to choose a low tolerance instead of a higher refinement of the mesh.

The simulations are performed using the annual average flow rate and the maximum flow rate, which took place on April 2014, taken in the Omaña river, the closest to the affected populations. Obviously it is extremely useful to have information on real data since this allows carrying out a reliable simulation, from the point of view of the parameters used and the results yielded by the numerical code. The maximum flow rate is the last flash flood that happened in that particular region. The return period of this event is estimated in one hundred years.

As initial condition we introduce dry terrain and the land uses have been introduced manually. As for the roughness coefficient, $0.025 \mu$ was taken for the river and bare soil, $0.18 \mu$ for scarce and dense vegetation, $0.02 \mu$ for infrastructures and $0.15 \mu$ for residential area. From the computational point of view a structured mesh is considered, with 630128 triangular elements (and 316187 nodes) with elements of two different sizes ( $5 \mathrm{~m}$ and $10 \mathrm{~m}$ ). The final time of the simulation is fixed in order to attain the stabilization of the output flow rate.

\section{RESULTS AND DISCUSSION}

Two different simulations have been carried out. The results obtained with the first of them are displayed in figure 2 and they have been done using the annual average water flow of the river Omaña, $8.30 \mathrm{~m}^{3} / \mathrm{s}$, calculated from the annual data of the last thirty years. The results shown in figure 2-A represent the depth, while those in figure 2-B represent the velocity. In this example the output time of the simulation is $7200 \mathrm{~s}$ (that is $2 \mathrm{hrs}$.) and the results are captured every minute. The simulation yields the zones of the river where the water follows the natural riverbed and the zones where the overflow is produced.

Concerning the second simulation, the initial datum taken into consideration is the maximum istantaneous flow rate of the hydrologic year 2013-2014 that was registered on April the $2^{\text {nd }} 2014$ with a value of $115.44 \mathrm{~m}^{3} / \mathrm{s}$. Results obtained for the depth and the velocity are shown in figures 3 and 4A. The simulation has been performed considering an output time of 1 hour, obtaining the results every minute. For the sake of providing a certain 
verification of the results obtained with the numerical simulation, some photos, taken in the region of interest, are shown in figure 5.

The second numerical example put forward two different situations. Firstly, it is selected and initial condition of dry terrain while in the other situation, an initial condition of wet terrain is used, with an initial water height of $0.40 \mathrm{~m}$ (like in an average depth of $5.03 \mathrm{~m}^{3} / \mathrm{s}$ ) which is the height of the water due to an average water flow rate obtained from experimental data (measured in the river). The results attained are similar in both cases (see figures $3 \mathrm{~A}$ and $4 \mathrm{~B}$ ) but the computation time is higher in the second case than in the first one.

As for the numerical scheme used, it is possible to choose among different options such as first and second order Roe scheme (see for instance $[9,13]$ for details on Roe scheme applied to shallow water models) and the decoupled hydrogeological discretization (DHD) scheme. See the work [9] for a detailed description of this latter method. As stated before, we have obtained analogous results with the different methods, all of them treat properly dry wet fronts (see [6]), which constitutes a hard task for more classical numerical schemes. Computation time is an important feature to be considered, which depends strongly on the processor used. In the computations presented in this work the type of processor utilized is i7 $4790(3.6 \mathrm{GHz})$. The computational cost of the first order Roe scheme tends to be smaller than that of the second order Roe scheme and the DHD scheme. In the simulations performed here, we use the first order Roe scheme, which runs faster than the other numerical schemes implemented in IBER. This is of especial interest in long-time simulations. 

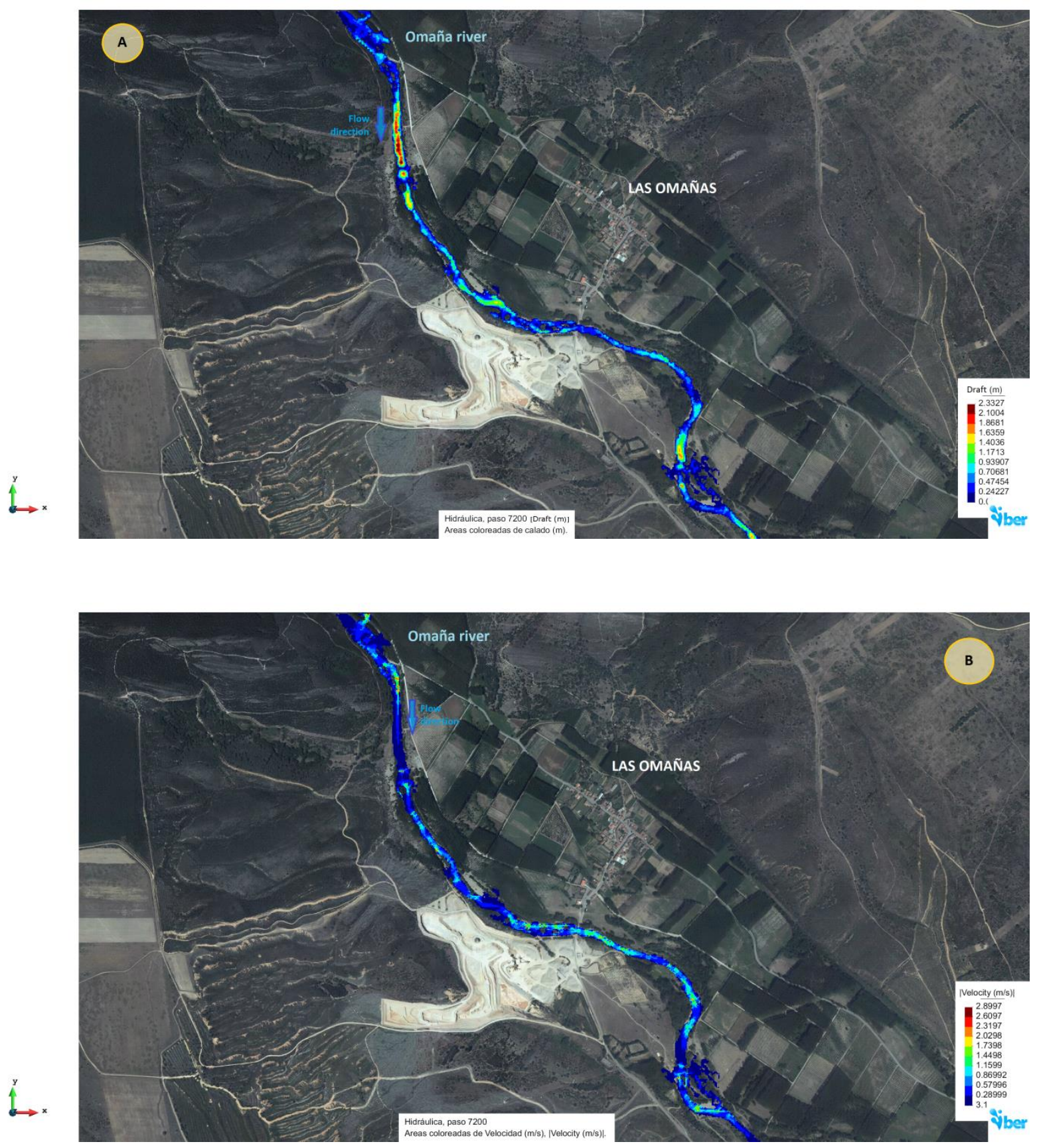

Fig. 2. Results of the simulation using data average flow records. Top frame, depicted with A, represents the depth, whilst bottom frame depicted with B represents the velocity.

The results depicted in figure 4 show that, after $1980 \mathrm{~s}$ (33 minutes of simulation time), the flood reaches the municipality of Las Omañas and also the road which crosses the river. In addition, the results show the different zones of the river where the water leaves its natural riverbed. 
As mentioned before, for a sort of verification of the results obtained in the event that took place in 2014, several pictures taken in that region (see figure 5) have been used. This a set of 5 pictures marked with the numbers 1 to 5 , representative of different locations. In the centre of figure 6 it can be seen an aerial view in which the five locations chosen are indicated. All the pictures were taken on April the $2^{\text {nd }}$ and the water sheets over the ground, close to the restaurant and the town hall.
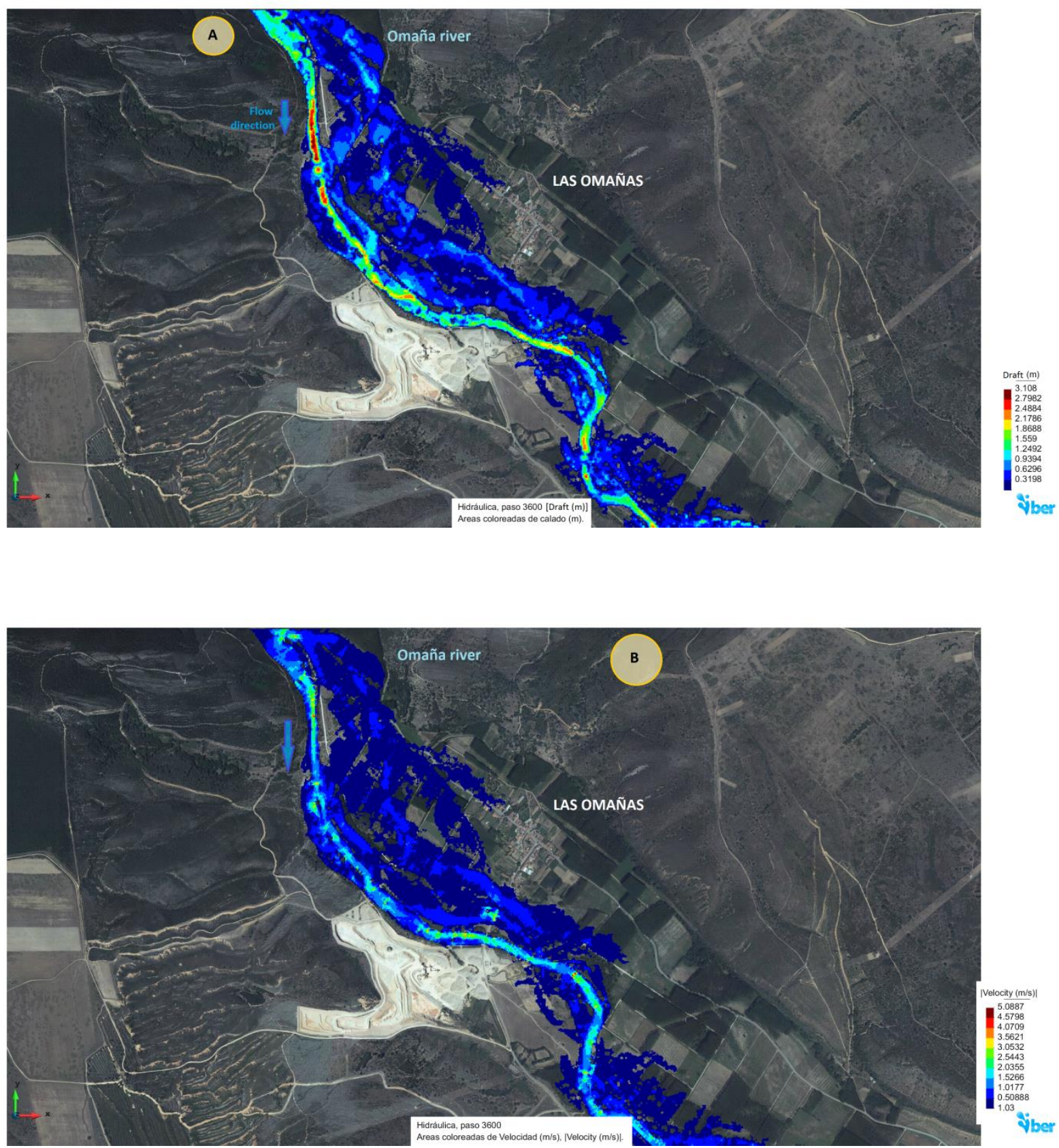

Fig. 3. Results of the simulation with data of 2013-2014 hydrologic year. Top frame, depicted with letter A, represents the depth. Bottom frame, depicted with letter B, represents the velocities. 

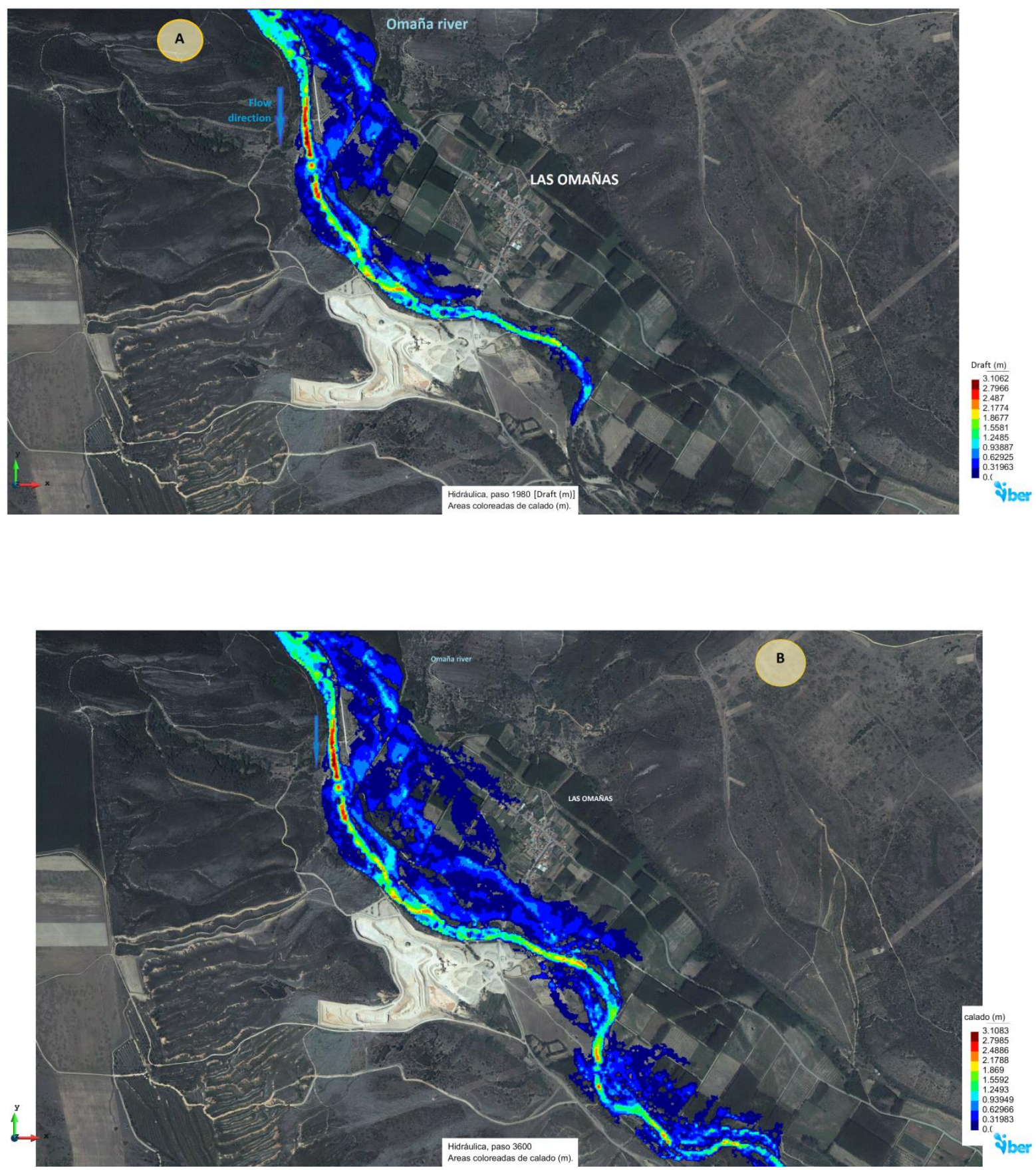

Fig. 4. Top frame, depicted with letter A: Results of the depth after 1980 seconds, considering data of April $2^{\text {nd }}$, 2014. Bottom frame, depicted with letter B: Results of the depth with wet terrain condition, using data of 2013-2014 hydrologic year. We remark that the village close to the river is starting to be affected.

We note that, according to the results depicted in figure $3 \mathrm{~A}$, the zone in which the pictures have been taken corresponds with a swamped region with a water sheet that reaches $30 \mathrm{~cm}$ in some places where the terrain is lower than the rest. Furthermore, in the pictures 1 and 2 it can 
be checked that the river does not overtops the bridge although it gets very close, since the bridge is high enough. However, in the margins, especially in the left one, the situation is different, since these zones are at the same level as the riverbed. This can be verified in pictures 3 to 5 .

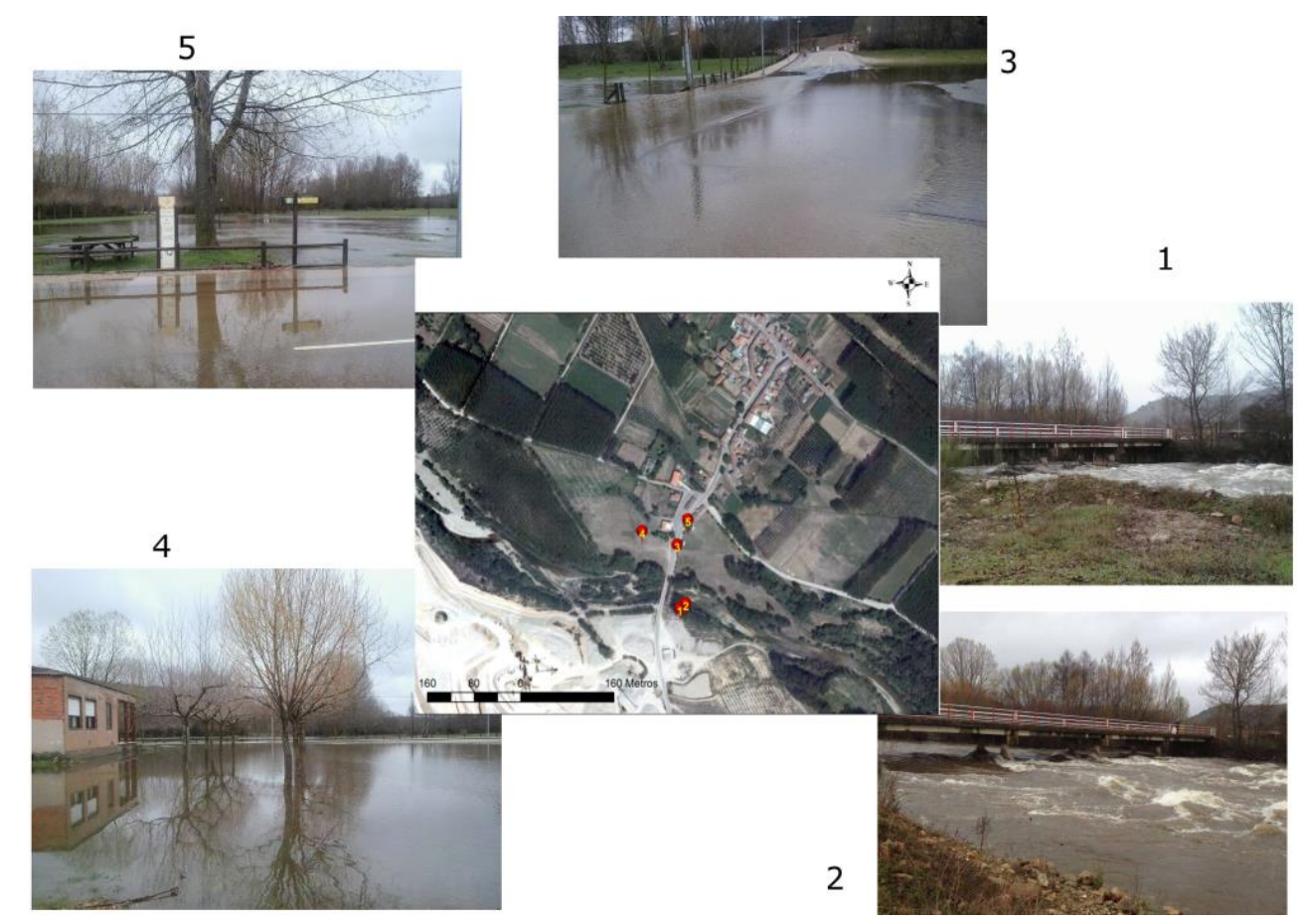

Fig. 5. Photographs taken during the April $2^{\text {nd }}, 2014$, and their location.

The results of these numerical examples indicate that preventive actions must be implemented in order to avoid serious damages to populated areas and also to agricultural ones. Both structural and non-structural actions (urban planning, assessment...) must be taken in order to mitigate the effects of floods. Among the structural measures we can consider the construction of dams to retain the water, the establishment of drainage systems, dikes to avoid water entering populated areas and also natural protections, among many others.

Using IBER, three dikes have been introduced in order to control the flooding of zones near populated areas. The height of the dikes have been selected to be $1.5 \mathrm{~m}$ above terrain level to avoid overflows, based on the height reached by the water in these points. The results can be seen in figure 6 . 

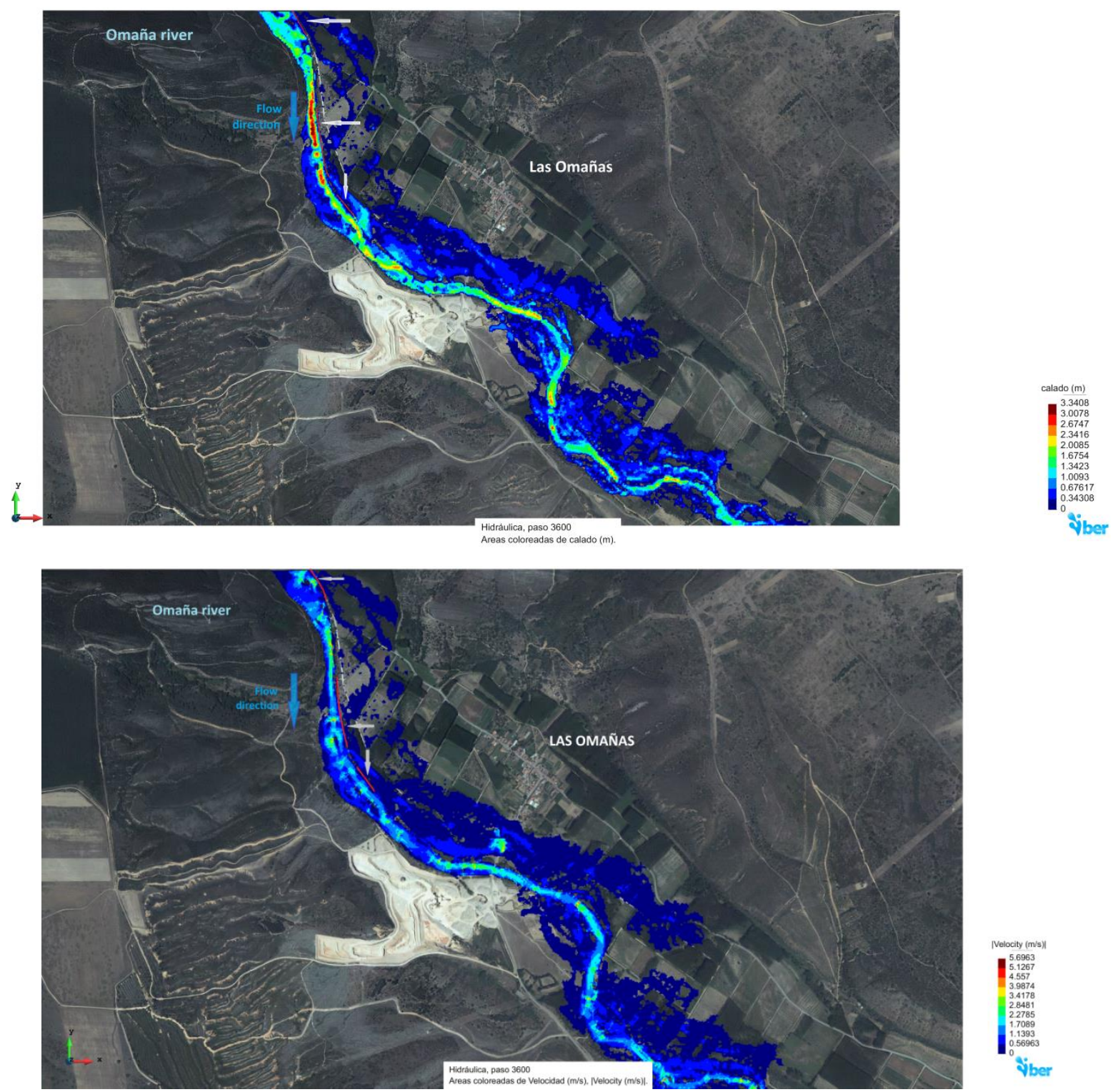

Fig. 6. Results of simulation with dikes to contain water. The arrows show the location of dikes. Top: Representation of the depth. Bottom: Representation of the velocities. We remark that the village close to the river is not affected by the flood, which confirms the right performance of the dikes.

If we compare the results shown in figure 6, where the dikes have been introduced, with those shown in figure $3 \mathrm{~A}$ (alternatively in figure 4B), we can see that the terrain occupied by water is smaller when dikes are inside. In this sense, we notice that in figure 4B, that is withouth dikes, the village is affected by the flood, while in figure 6 , that is with dikes, the village is unaffected. 
The results obtained are encouraging, since they indicate that it is possible to control the inundation of populated areas, whereas it is necessary to introduce other measures to avoid flooding in the whole area.

However, we must be aware of the fact that the effect of the structural actions can be the contrary to the expected one if these structures fail, e.g. due to a dam break or an improper use of the regulation of the flow rate.

\section{CONCLUSIONS}

In this work we have performed a numerical simulation of floods that take place in the vicinity of the confluence of two rivers that affect population in the flooding area and also crops. The results have been obtained using information from a region in NW Spain, called Las Omañas, but the same methodology can be applied to other regions with similar features. Two numerical simulations have been carried out with freeware IBER. In the first case we have considered the annual average water flow of the river Omaña which has been calculated from the annual data of the last thirty years. The second one has been performed taking as initial datum the maximum istantaneous flow rate of the hydrologic year 2013-2014. In this latter case the results of the simulation indicate that the river overtops its banks and invades the village. These results agree with several pictures taken in that zone and shown in this work.

During the study, initial conditions about the terrain (wet or dry) have been compared and, in this case of a big flood, the results are quite similar. Due to the fact that the wet terrain entails more computational time, it is more advisable to work with dry terrain initial conditions.

Among the numerical schemes to solve the Riemann problems appearing at cell interfaces we have chosen the first order Roe scheme as it is the fastest one.

In the particular case of Las Omañas, the results obtained in the simulations indicate that it is necessary to implement structural measures like dikes to contain the water. We have introduced three dikes in the model which yield good results. As future lines we consider that it is necessary to implement other actions complementary to the dikes, mainly non-structural performances, which are less expensive and could help improve the effectiveness of protective measures. 


\section{ACKNOWLEDGEMENTS}

The authors would like to thank the Spanish Agency of Meteorology (AEMET) for supplying meteorological information. This work has been carried out during the $\mathrm{PhD}$ studies of the first author.

\section{REFERENCES}

1. Areu-Rangel, O.S., González-Cao, J., Crespo. A.J.C. \& Bonasia, R., Numerical modelling of hydrological safety assignment in dams with IBER, Sustanaible Water Resouces Managment, 2007, pp. 1-12.

2. Arnell, N.W. and Gosling, S.N., The impacts of climate change on river flood risk at the global scale, Climatic Change, 2016, vol. 134 (3), pp. 387-401.

3. Aroca-Jiménez, E., Bodoque, J.M. and García, J.A. \& Díez-Herrero, A., Analysis of Social Vulnerability to Flash Floods in Urban Areas of Castilla y León (Spain), International Conference of Urban Risks in Lisbon - ICUR, 2016, pp. 1-8.

4. Bodoque, J.M., Díez-Herrero, M., García, J.A., Cortés, B., Ballesteros-Cánovas, J.A. \& Olcina, J., Improvemet of resilience of urban areas by integrating social perception in flash-flood risk management, Journal of Hydrology, 2016, vol. 541 (Part A), pp. 665-676.

5. Cea, L., An unstructured finite volume model for unsteady turbulent shallow water flow with wet-dry fronts: numerical solver and experimental validation. Ph. Tesis, Univ. A Coruña, 2005.

6. Cea, L., Puertas, J. and Vazquez-Cendon, M.-E., Depth averaged modelling of turbulent shallow water flow with wet-dry fonts, Archives of Computational Methods in Engineering, 2007, vol. 14 (3), pp. 303-341

7. Cea, L. \& Vazquez-Cendon, M.E., Unstructured finite volume discretisation of bed friction and convective flux in solute transport models linked to the shallow water equations, Journal of Computational Physics, 2012, vol. 231, pp. 3317-3339. doi: 10.1016/j.jcp.2012.01.007

8. Churuksaeva, V. and Starchenko, A. 2015. Mathematical Modeling of a River Stream Based on a Shallow Water Approach. Procedia Computer Science. 66, 200-209.

9. Cea, L., Bladé, E., A simple and efficient unstructured finite volume scheme for solving the shallow water equations in overland flow applications. Water Resources Research, 2005, vol. 51 (7), pp. 5464-5486. 
10. Cea, L., Bermúdez, M., Puertas, J., Bladé, E., Corestein, G., Escolano, E., Conde, A., Bockelmaann-Evans, B. and Ahmadian, R., IberWQ: new simulation tool for 2D water quality modelling in rivers and shallow estuaries, Journal of Hydroinformatics, 2016, vol. 19 (4).

11. Corestein, G., Bladé, E., Cea, L., Lara, A., Escolano, E. \& Coll, A., Iber, a river dynamics simulation tool. M. Pasenau, E. Escolano, J. Suit, A. Coll, A. Melendo, A. Monros (Eds.), et al., GiD 2010, 5th Conference on Advances and Applications of GID. Monografía CIMNE M118, International Center for Numerical Methods and Engineering, Barcelona, 2016, vol. 87.

12. Cutter, S.L., Bryan J. Boruff, W. Lynn Shirley, Social Vulnerability to Environmental Hazards, Social Science Quarterly, 2003, vol. 84 (2), pp. 529-539.

13. Dumbser, M., Castro M., Parés, C. and Toro, E.F., ADER schemes on unstructured meshes for nonconservative hyperbolic systems: Applications to geophysical flows, Computers \& Fluids, 2009, vol. 38 (9), pp. 1731-1748.

14. Fe, J., Cueto-Felgueroso, L., Navarrina, F.\& Puertas, J., Numerical viscosity reduction in the resolution of the shallow water equations with turbulent term, International Journal for Numerical Methods in Fluids, 2009, vol. 58 (7). doi: 10.1002/fld.1759

15. Hidalgo, A. \& Dumbser, M., High-Order One-Step Schemes For Non-Conservative PDE: Application To Shallow Water Systems, Water - infinitely deformable but still limited. 2nd IAHR Europe Congress, 2012, TUM. Munich (Germany).

16. Marchi, L., Borga, M., Preciso, E. \& Gaume, E., Characterisation of selected extreme flash floods in Europe and implications for flood risk management, Journal of Hydrology, 2010, vol. 394 (1-2), pp. 118-133.

17. Martínez-Cantó, R. and Hidalgo, A., Modelización de inundaciones fluviales con iber. Caso práctico de Santiago del Molinillo (León, Spain). Modelling of fluvial inundations with iber. Case study in Santiago del Molinillo (León, Spain), Revista de las Ciencias geomáticas, 2016, vol. 34, pp. 7-12.

18. Rodríguez de la Torre, A., Álvarez Gordón, R., Gras, J., García Rubí, P. and Rollán, R., Flood management in reservoirs in upper river basins from real time data collection by using downstream alert systems. In: Dams and reservoirs, societies and environment in the 21st Century. 2006, vol. 1 y 2. L. Berga, J.M. Buil, E. Bofill, J.C. de Cea, J.A. García Pérez, G. Mañueco, J. Polimon, A. Soriano y J. Yagüe. Taylor \& Francis Group. 
19. Toro, E.F., Shock-Capturing methods for free-surface shallow flows. Ed. J. Wiley \& Sons, LTD, 2001.

20. Versteeg, H.K. and Malalasekera, W., An introduction to computational fluid dynamics: the finite volume method. Pearson Education, 2007. 


\section{LIST OF FIGURE CAPTURES}

Fig. 1. Geographical situation of the study area.

Fig. 2. Results of the simulation using data average flow records. Left frame, depicted with A, represents the depth, whilst right frame depicted with B represents the velocity.

Fig. 3. Results of the simulation with data of 2013-2014 hydrologic year. Left frame, depicted with letter A, represents the depth. Right frame, depicted with letter B, represents the velocities.

Fig. 4. Left frame, depicted with letter A: Results of the depth after 1980 seconds, considering data of April $2^{\text {nd }}, 2014$. Right frame, depicted with letter B: Results of the depth with wet river terrain condition, using data of 2013-2014 hydrologic year. We remark yhat the village close to the river is starting to be affected.

Fig. 5. Photographs taken during the April $2^{\text {nd }}, 2014$, and their location.

Fig. 6. Results of simulation with dikes to contain water. The arrows show the location of dikes. Top: Representation of the depth. Bottom: Representation of the velocities. We remark that the village close to the river is not affected by the flood, which confirms the right performance of the dikes. 